\title{
Las evidencias benefician al sistema de salud: reforma para remediar el gasto catastrófico y empobrecedor en salud en México
}

\author{
Felicia Marie Knaul, PhD,(1) Héctor Arreola-Ornelas, MSc, (1) Oscar Méndez-Carniado,, ${ }^{(1)}$ Chloe Bryson-Cahn,,
} Jeremy Barofsky, ${ }^{(2)}$ Rachel Maguire, ${ }^{(3)}$ Martha Miranda, MSc, ${ }^{(4)}$ Sergio Sesma, MSc. ${ }^{(5)}$

\begin{abstract}
Knaul FM,Arreola-Ornelas H, Méndez-Carniado O, Bryson-Cahn C, Barofsky J, Maguire R, Miranda M, Sesma S. Las evidencias benefician al sistema de salud: reforma para remediar el gasto catastrófico y empobrecedor en salud en México.

Salud Publica Mex 2007;49 supl I:S70-S87.
\end{abstract}

\section{Resumen}

La falta de protección financiera en salud es una enfermedad recientemente diagnosticada de los sistemas de salud. El síntoma más obvio es que las familias enfrentan la ruina económica y el empobrecimiento por financiar su atención médica. México fue uno de los primeros países en diagnosticar el problema, atribuirlo a la falta de protección financiera y proponer una terapia sistémica a través de la reforma del sistema de salud. Este trabajo analiza la manera en que México convirtió las evidencias sobre los gastos catastróficos y empobrecedores en salud en un catalizador de la renovación institucional a través de la reforma que creó el Seguro Popular de Salud (SPS). Presentamos tanto las tendencias de los últimos 15 años sobre la evolución de los gastos catastróficos y emprobrecedores en salud, como las evidencias recientes sobre el mejoramiento en estos indicadores con la expansión del SP. Los resultados de la experiencia mexicana sugieren que la organización y el financiamiento del sistema de salud han jugado un papel muy importante en la reducción del empobrecimiento y en la protección de los hogares durante los periodos de crisis financiera individual y colectiva.

Palabras clave: financiamiento de la salud; reforma del sistema de salud; sistemas de salud; protección financiera; gastos catastróficos y empobrecedores en salud; política de salud basada en evidencias; México
Knaul FM, Arreola-Ornelas H, Méndez-Carniado O, Bryson-Cahn C, Barofsky J, Maguire R, Miranda M, Sesma S. Evidence is good for your health system: policy reform to remedy catastrophic and impoverishing health spending in Mexico.

Salud Publica Mex 2007;49 suppl I:S70-S87.

\section{Abstract}

Absence of financial protection in health is a recently diagnosed "disease" of health systems. The most obvious symptom is that families face economic ruin and poverty as a consequence of financing their health care. Mexico was one of the first countries to diagnose the problem, attribute it to lack of financial protection, and propose systemic therapy through health reform. In this article we assess how Mexico turned evidence on catastrophic and impoverishing health spending into a catalyst for institutional renovation through the reform that created Seguro Popular de Salud (Popular Health Insurance). We present 15-year trends on the evolution of catastrophic and impoverishing health spending, including evidence on how the situation is improving. The results of the Mexican experience suggest an important role for the organisation and financing of the health system in reducing impoverishment and protecting households during periods of individual and collective financial crisis.

Key words: financing health; health care reform; health systems; financial policy; catastrophic and impoverishing health spending; evidence-based health policy; Mexico

Traducción publicada con permiso. La versión original en inglés se encuentra en: Lancet 2006;368:1828-I84I. Disponible en: http://www.thelancet.com

(I) Fundación Mexicana para la Salud. México.

(2) Harvard Initiative for Global Health. Cambridge, MA.

(3) Institute for the Future. San Francisco. EUA.

(4) Conferencia Interamericana de Seguridad Social. México.

(5) Investigador independiente. 
M uchos países de ingresos medios están inmersos en procesos interrelacionados de transición demográfica, epidemiológica, de la salud y económica. Esta situación plantea cambios complejos para los sistemas de salud y, al mismo tiempo, constituye una oportunidad y un catalizador para la renovación institucional. Uno de los retos más importantes que enfrentan los sistemas de salud es generar mecanismos de financiamiento eficientes, justos y sustentables que ofrezcan una protección financiera universal.

La falta de protección financiera es una enfermedad de reciente diagnóstico de los sistemas de salud. Después de la identificación de las elevadas tasas de gasto catastrófico y empobrecedor en salud (GCES) en muchos países, la enfermedad fue reconocida internacionalmente. Se están desarrollando, probando y aplicando tratamientos a nivel del sistema de salud, y los avances están siendo monitoreados y evaluados. El síntoma más evidente de esta enfermedad es que las familias no sólo sufren la carga de la enfermedad, sino también la ruina económica y el empobrecimiento derivados de financiar la atención médica con sus propios recursos.

El reconocimiento internacional de este importante reto para los sistemas de salud ha aumentado en el último lustro. La mayor conciencia de ello a nivel nacional y a nivel mundial se ha enfocado en el riesgo que enfrentan los hogares de caer en la pobreza, de profundizar su nivel de empobrecimiento o de enfrentar graves quebrantos financieros debido al gasto en salud. A menudo esto obliga a las familias a vender su patrimonio o a reducir su inversión en educación, alimentación y vivienda.

Consciente de esto, la $58^{\mathrm{a}}$ Asamblea Mundial de Salud reunida en mayo de 2005 adoptó una resolución que reconoce la ausencia en la mayoría de los países en desarrollo de mecanismos de protección financiera que ofrezcan un prepago y la agrupación de los riesgos. ${ }^{1}$ En un llamado a todos los estados miembros, la Asamblea les solicitó que compartan sus experiencias en materia de métodos de financiamiento a la salud, incluido el desarrollo de esquemas de seguridad social de salud, y haciendo particular énfasis en los mecanismos institucionales que se implementan para financiar los sistemas de salud.

México fue uno de los primeros países en diagnosticar el problema de los gastos catastróficos y emprobrecedores en salud derivados del pago de los mismos con gasto de bolsillo, así como en atribuir su causa a la falta de protección financiera y proponer una terapia sistémica a través de una reforma del sistema de salud. Este documento tiene el propósito de analizar con detalle un aspecto específico de la reciente experiencia mexicana relativa a la reforma del sistema de salud: el gasto catastrófico y empobrecedor en salud (GCES). El trabajo describe el proceso y presenta tanto las tendencias para los últimos 15 años como las evidencias recientes sobre la manera en que el gasto en salud está evolucionando paralelamente a la reforma.

El trabajo está organizado como sigue: primero se revisan las evidencias metodológicas y descriptivas a nivel internacional sobre las razones por las que la falta de mecanismos de prepago, protección financiera y agrupación de riesgos son problemas mundiales que exigen soluciones locales, basadas en evidencias. A continuación se hace una breve descripción de los aspectos clave de la reforma relacionados con el GCES. Después se analiza cómo y por qué el problema del GCES en México se convirtió en una prioridad de las políticas, en uno de los principales mensajes de la reforma y en un motor del cambio social. Luego se presenta el análisis de la evolución y los determinantes del gasto catastrófico y empobrecedor en salud en México entre 1992 y 2004 usando las Encuestas Nacionales de Ingresos y Gastos de los Hogares (ENIGH)² -ésta es la serie temporal más larga que se haya presentado sobre un país en desarrollo y abarca tanto un periodo de crisis económica (1994-1996), como los primeros años de la reforma del sistema de salud (2002-2004)-. Es posible, por ende, observar la forma en que los gastos de bolsillo en salud realizados por los hogares se han desarrollado junto a la política económica y de salud. Se analizan también las tendencias a través del tiempo del GCES y de la proporción y brecha de la pobreza. El trabajo también presenta un análisis de regresión de la Encuesta Nacional de Salud y Nutrición (ENSANUT) 2006. ${ }^{3}$ Después se analiza la experiencia mexicana para extraer las lecciones para la política a nivel mundial.

Las tendencias a través del tiempo demuestran que el mejoramiento del GCES en la poscrisis coincide con los programas tanto de la reforma del sistema de salud como de recuperación económica y alivio de la pobreza, como Oportunidades (un programa integral de desarrollo social y alivio de la pobreza que incluye componentes de salud, nutrición, microfinanciamiento y educación, y abarca a la mayoría de los hogares que viven en la pobreza en México). ${ }^{4,5}$ Las tendencias en los indicadores y el análisis econométrico sugieren una asociación entre la reducción del gasto de bolsillo y del gasto catastrófico por parte de los hogares y la expansión del Seguro Popular de Salud (SPS). Los datos no son suficientes para atribuir una causalidad en esta asociación, pero se están emprendiendo estudios del gasto catastrófico y empobrecedor que forman parte de la evaluación formal, externa y aleatorizada del Seguro Popular de Salud, ${ }^{6}$ y utilizando las ENIGH más recientes (no disponibles al momento de publicar la versión original de este documento). 


\section{El gasto emprobrecedor y catastrófico en salud es un reto mundial}

Los sistemas de salud se financian principalmente a través de tres mecanismos: el dinero recaudado por el Estado vía los impuestos específicos y generales; las contribuciones a la seguridad social vía las deducciones o los impuestos, y los pagos privados, que pueden ser de bolsillo al momento de recibir la atención o por primas de seguros privados. La composición del financiamiento por estas tres categorías principales tiende a variar sustancialmente entre los países.7.8

Los impuestos generales y los impuestos sobre la nómina son prepagados, progresivos e involucran un grado sustancial de agrupación de riesgos. De cualquier manera, estos esquemas de seguridad social financiados por el gobierno pueden proteger a todos los ciudadanos contra los gastos catastróficos y empobrecedores en salud, pero con frecuencia no lo hacen. Ciertos grupos quedan excluidos -típicamente los pobres y los trabajadores independientes, e informales, no asalariados-.

Un sistema financiado con el gasto de bolsillo es considerado como el medio menos eficiente y más desigual de sostener el sistema de salud. ${ }^{9,10}$ En esos sistemas hay poca oportunidad para la agrupación de los riesgos, existe una menor competencia entre los proveedores y los pacientes pagan más de lo que pagarían bajo un esquema de prepago, debido a la fragmentación de los riesgos y a la urgencia del tratamiento. Como consecuencia, la mayor carga recae sobre la familia. Cuando el costo de la atención rebasa la capacidad de pago al momento del servicio, ocurren los gastos catastróficos y potencialmente empobrecedores, o la atención necesaria se pospone. Muchas veces las familias se ven obligadas a elegir entre la satisfacción de otras necesidades básicas, como educación, alimentación y vivienda, y el pago de la atención médica y salvar a los seres queridos de la enfermedad, el sufrimiento y, con frecuencia, de una reducción de la esperanza de vida.

El gasto de bolsillo es perjudicial para los hogares, pero también lo es para la economía. Hay una relación inversa entre el nivel de desarrollo económico de un país y el grado en que el sistema de salud está financiado por el gasto privado de bolsillo (figura 1). Esto probablemente refleja muchos factores, y la relación muy bien podría ser dual -la cobertura del seguro de salud es tanto un determinante como un resultado del desarrollo económico-.

Las evidencias descriptivas apoyan estas teorías. El financiamiento de los sistemas de salud con gasto de bolsillo está generando un riesgo importante y global que afecte todos los países. En un reciente Informe de Políticas, la OMS muestra, para una serie de países, una asociación negativa importante entre la proporción de los hogares con gastos catastróficos en salud y la proporción de gasto de bolsillo respecto al gasto total en salud. ${ }^{11}$ El gasto en salud es también una impor-

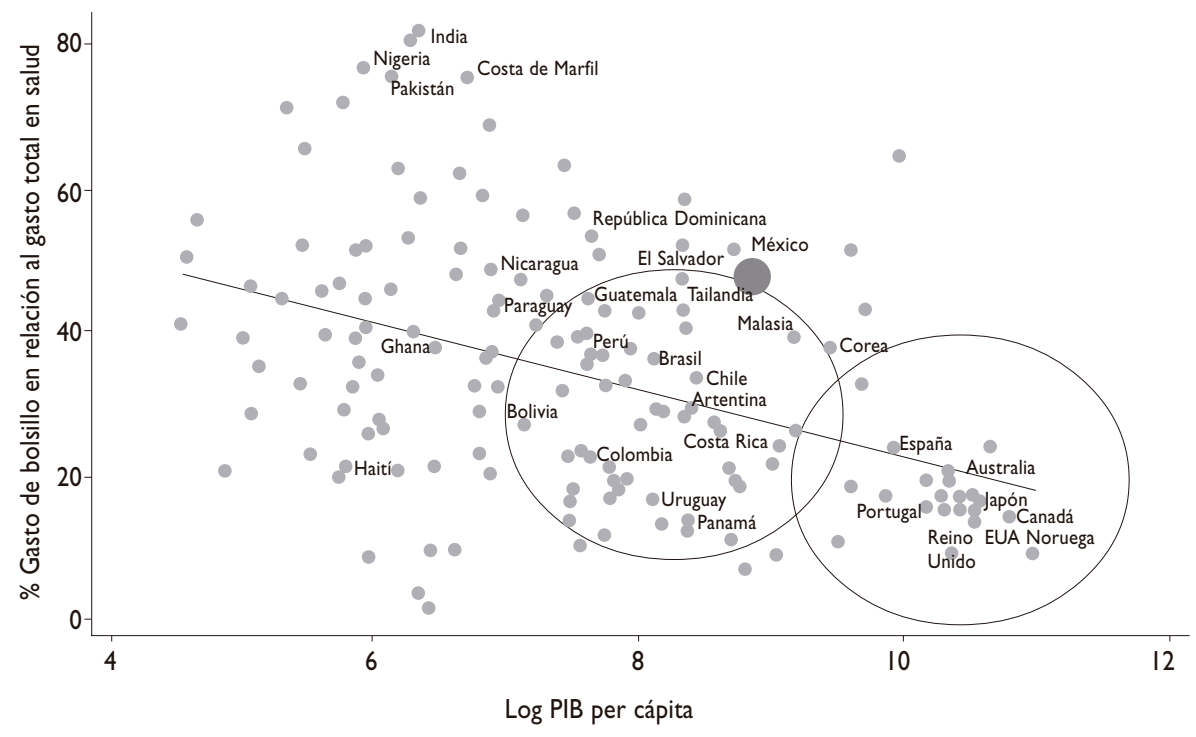

Fuente: Estimaciones de los autores basadas en datos del Banco Mundial (2003) y la OMS (2003)

Figura I. Gasto de bolsillo como proporción del gasto total en salud en relación al Pib per cápita 
tante fuente adicional de pobreza. ${ }^{12} \mathrm{Si}$ los hogares caen en trampas de pobreza debido a crisis de salud, ya que no pueden asegurarse contra la enfermedad, este fenómeno puede tener implicaciones tanto en el corto como en el largo plazo. ${ }^{13}$

El gasto de bolsillo para atención en salud es más común en los países en vías de desarrollo que en países de ingresos altos. Un análisis de once países que representan $79 \%$ de la población asiática concluye que los pagos de bolsillo siguen siendo el principal medio de financiar la atención médica en gran parte de Asia y amenazan con empobrecer a millones de personas. ${ }^{12}$ Las estimaciones muestran que otros 78 millones de personas, $2.7 \%$ de la población total, se ubica debajo del umbral de pobreza extrema de 1 dólar al día después de considerar los gastos en atención médica. Esto representa un aumento de $14 \%$ en la tasa de pobreza extrema y una amenaza al bienestar que no se ha incorporado en las estimaciones existentes de la pobreza.

Aun los ciudadanos de los países más ricos que no ofrecen protección financiera universal en salud corren el riesgo de una catástrofe por motivo de los gastos en salud. En Estados Unidos, un país donde un gran segmento de la población más pobre no tiene acceso a un seguro de salud, las evidencias recientes muestran que el gasto en salud contribuye a una gran proporción de las reclamaciones de bancarrota. ${ }^{14}$

Dado este riesgo global, ¿cúantas familias son afectadas? Determinar una medida mundial del número de familias afectadas por los gastos catastróficos o empobrecedores en salud es tarea difícil. En un reciente Informe de Políticas, la OMS estimó que más de 44 millones de hogares enfrentan una catástrofe financiera anualmente y que alrededor de 25 millones de hogares son empujados a la pobreza. ${ }^{1}$ Lo anterior es también el caso si se reduce el punto de corte para lo que se define como gasto catastrófico y hasta la fecha existe debate sobre el nivel correcto. Estas cifras anuales se basan en una medida del gasto en salud como proporción del ingreso anual. Nuestro análisis sugiere que el número de hogares afectados puede ser incluso mayor si el gasto en salud se analiza durante un periodo más corto, el cual es más apropiado para las familias que viven en la pobreza, cuyo ingreso es insuficiente para cubrir sus necesidades básicas. Finalmente, un análisis dinámico o acumulado -como el número de hogares que sufren un GCES en algún momento en un año.

Además, estas cifras miden sólo a las familias que de hecho han tenido gastos catastróficos o se han empobrecido debido a los gastos en salud. El alcance potencial de la falta de protección financiera es mucho mayor. En primer lugar, hay que considerar a todos los hogares que han tenido una catástrofe de salud -in- cluidas la pérdida permanente del bienestar, la discapacidad y la muerte- porque no pueden pagar la atención médica y por lo mismo su gasto es bajo. Después hay que considerar a los hogares en riesgo de una catástrofe financiera -todos los que no cuentan con protección financiera en salud-. Finalmente, esto no sólo está en función de la proporción de familias que tienen acceso a un esquema de aseguramiento o seguridad social, ya sea público o privado. También está en función de los servicios que se incluyen en cada paquete, por lo que hay que incluir a las familias con protección financiera parcial.

Muchos países latinoamericanos basan el financiamiento de sus sistemas de salud en el gasto de bolsi1lo. ${ }^{15}$ Típicamente, el sector formal del mercado laboral está cubierto por el sistema público de seguridad social, y el sector informal, los trabajadores independientes y quienes están fuera de la fuerza laboral reciben prestaciones en salud limitadas, a través de una variedad de esquemas subfinanciados del sector público que no incluyen derechos específicos a un paquete de atención médica. El actual sistema de salud mexicano fue fundado bajo dicho modelo hace más de seis décadas y en 2003 fue reestructurado como respuesta a esta problemática.

\section{Antecedentes de la Reforma}

Únicamente mencionamos los elementos de la reforma necesarios para entender mejor los resultados que se presentan más abajo. Se sugiere a los lectores consultar los otros trabajos dentro de esta serie, ${ }^{16,17}$ y los que se incluyen en la bibliografía para una descripción de la reforma del sistema de salud.*

La reforma estructural del sistema mexicano de salud de 2003 fue diseñada para aumentar la protección financiera ofreciendo un seguro de salud subsidiado, dirigido a los 50 millones de mexicanos que no tienen cobertura de la seguridad social y que se concentran entre los más pobres. La reforma a la Ley General de Salud fue aprobada en abril de 2003 y entró en vigor el $1^{\circ}$ de enero de $2004 .{ }^{18}$ El núcleo de la reforma que creó el nuevo Sistema de Protección Social en Salud (SPSS) es el Seguro Popular de Salud (SPS). La reconfiguración de las fuentes y la asignación de los

\footnotetext{
* Los trabajos que fueron publicados posteriormente a la serie original en Lancet incluyen: Secretaría de Salud. Sistema de protección social en salud. Elementos conceptuales, financieros y operativos. 2da. edición. México: SSA/Funsalud/INSP/FCE, 2006, y Ortiz M. El Seguro Popular. Una crónica de la democracia mexicana. México: SSA/Funsalud/INSP/FCE, 2006.
} 
recursos vía la reforma busca aumentar la eficiencia y la equidad del financiamiento, así como la protección financiera de los hogares. ${ }^{19}$ La transición de siete años hacia una cobertura voluntaria universal se tradujo en una meta de afiliación anual de $14.3 \%$ de las aproximadamente 12 millones de familias no aseguradas. Conforme a lo estipulado por la ley, el proceso de afiliación se ha enfocado en el quintil más pobre de la población y, en consecuencia, la fase de transición ha sido altamente progresiva.

La gradualidad de la expansión del SP a lo largo del tiempo y la afiliación de las familias es lo que posibilita hacer el análisis de regresión que se presenta más abajo. Entre 2001 y 2003, antes de la reforma, el SP operaba como un programa piloto y se afiliaron a él 614000 familias. ${ }^{20}$ Para fines de 2004, más de 1.7 millones de familias se habían inscrito; para fines de 2005 la cifra era de más de 3.5 millones, y en septiembre de 2006 el número de familias afiliadas llegó a 4 millones. ${ }^{21,22}$

Las 32 entidades federativas de que se compone México entraron al programa en forma gradual entre 2001 y 2005. De manera similar, la cobertura dentro de los estados y la expansión geográfica han sido graduales y, mientras algunas entidades han logrado cobertura universal, en otras sólo las familias que viven en ciertos municipios que cuentan con SP pueden inscribirse. Con base en los datos de afiliación de la Comisión Nacional de Protección Social, en 2002, 342 municipios participaron en el programa piloto, en 2003 eran 524 y en 2004 un total de 946. Para fines de 2005, casi 1600 de los 2454 municipios tenían familias afiliadas.

La expansión de la protección financiera depende no solamente de a quién se cubre, sino también de qué es lo que incluye el paquete de servicios. Esto abarca tres dimensiones: servicios y tecnologías, enfermedades y calidad de la atención. En México la expansión de la reforma es precisamente un proceso interrelacionado para cubrir a más gente, más intervenciones y más enfermedades con una mejor calidad. ${ }^{17} \mathrm{La}$ expansión del paquete y el mejoramiento de la calidad son cuestiones centrales para la reforma y ambas se exponen en diferente medida en cada uno de los trabajos de la serie. . $^{6,16,17,23,24}$

\section{El gasto en salud catastrófico y empobrecedor en México: un catalizador de la reforma del sistema de salud de 2003 y para el Seguro Popular de Salud}

En esta sección, se analiza cómo las evidencias descriptivas sobre la naturaleza catastrófica del gasto en salud de las familias fueron un mecanismo catalizador que inspiró y dirigió el cambio en las políticas. El análisis de la protección financiera se ha usado constantemente en todas las fases de la reforma mexicana en salud, que incluyen el diseño de la política, la presupuestación, el monitoreo y la evaluación, la construcción de consensos, la evaluación comparativa de desempeño, el diseño de incentivos y la difusión de los resultados. Aunque este es tan sólo uno de los muchos tipos de evidencia que se han incorporado al proceso de la reforma, fue uno de los más importantes. ${ }^{6,16,17}$

Identificamos cuatro periodos en el desarrollo y el uso de las evidencias sobre la protección financiera en salud en México: el problema se identificó entre principios y mediados de la década de 1990; luego el análisis a nivel nacional se integró al trabajo mundial de la OMS enfocado hacia la justicia financiera; ${ }^{9}$ entre 2000 y 2003, el periodo de la prerreforma, las evidencias tanto nacionales como internacionales fueron particularmente sobresalientes en términos de diseño de los proyectos de prerreforma del SP, el cabildeo con legisladores y la construcción de consensos dentro y fuera del sector, y, a partir de 2003, se han usado las evidencias a nivel nacional para reforzar la implementación y la evaluación, así como para guiar las siguientes etapas del proceso de implementación de la reforma. El trabajo analítico en las secciones finales de este estudio contribuye a esta fase más reciente (cuadro I).

¿Cómo y por qué las evidencias sobre la protección financiera jugaron un papel tan destacado en el proceso de las políticas detrás de la reforma? A principios de la década de 1990 se lanzaron en México varias iniciativas importantes de investigación que incluyeron una nueva línea de trabajos analíticos sobre el financiamiento de la salud, emprendidas en forma conjunta por los especialistas en salud y los economistas. El Instituto Nacional de Salud Pública (INSP) y la Fundación Mexicana para la Salud (Funsalud) encabezaron estos análisis y para ello recurrieron a investigaciones y metodologías novedosas a nivel internacional, como las cuentas nacionales de salud. ${ }^{10}$ Esta investigación proporcionó insumos clave para la reforma de 2003. Además, demostró -casi una década antes de la reforma- que el sistema mexicano de salud dependía demasiado del gasto de bolsillo como fuente de financiamiento. Esta información rompió con el supuesto común y erróneo de que el sistema de salud era financiado en su mayoría por el gobierno a través de los recursos públicos. ${ }^{16}$

Las evidencias condujeron a investigaciones sustanciales sobre las fuentes y los usos del financiamiento de la salud, y este trabajo incluyó la generación de un conjunto de datos y encuestas, así como la capacitación de los investigadores. También es importante reconocer que México tuvo una gran ventaja para este trabajo -la ENIGH se había realizado con regularidad durante varios años-. ${ }^{2}$ La historia y la continuidad de estas en- 


\section{Cuadro I \\ EVIDENCIAS SOBRE PROTECCIÓN FINANCIERA COMO UN INSUMO PARA LAS POLÍTICAS: I 992-2006}

\begin{tabular}{|c|c|}
\hline $\begin{array}{l}\text { Diagnóstico } \\
\text { 1992-1997 }\end{array}$ & $\begin{array}{l}\text { - Trabajo desde la Fundación Mexicana para la Salud } \\
\text { con la Universidad Harvard y el Banco Mundial que } \\
\text { mostró que el financiamiento público no era el que } \\
\text { predominaba en el sistema de salud } \\
\text { - Evidencias para catalizar la investigación y el co- } \\
\text { nocimiento }\end{array}$ \\
\hline $\begin{array}{l}\text { Reconocimiento } \\
\text { global } \\
\text { I998-2000 }\end{array}$ & $\begin{array}{l}\text { - Desarrollo del modelo de la OMS para la evalua- } \\
\text { ción del desempeño de los sistemas de salud inclu- } \\
\text { yendo justicia en el financiamiento y protección } \\
\text { financiera } \\
\text { - Ordenamientos globales y evidencias }\end{array}$ \\
\hline \multirow{3}{*}{$\begin{array}{l}\text { Prerrefoma } \\
2000-2002\end{array}$} & $\begin{array}{l}\text { - El equipo de transición del presidente electo iden- } \\
\text { tificó las prioridades en salud y del sistema de sa- } \\
\text { lud y formuló propuestas para el aseguramiento } \\
\text { universal en salud (2000) } \\
\text { - Evidencia global como catalizador de una re- } \\
\text { forma nacional, identificación de prioridades y } \\
\text { la política }\end{array}$ \\
\hline & $\begin{array}{l}\text { - Incorporación del Programa del Seguro Popular } \\
\text { como una estrategia en el Programa Nacional de } \\
\text { Salud } 200 \mathrm{I}-2006(200 \mathrm{I}) \\
\text { - Evidencias para el diseño de políticas } \\
\text { - Piloteo a gran escala del Seguro Popular de Salud, } \\
\text { 2002-2003 } \\
\text { - Incorporación de un esquema de evaluación }\end{array}$ \\
\hline & $\begin{array}{l}\text { - Reforma a la Ley General de Salud, } 2003 \\
\text { - Evidencias para construcción de consensos } \\
\text { - La reforma entra en operación, I de enero de } 2004 \\
\text { - Evidencias para el diseño de políticas específicas, } \\
\text { la presupuestación y la evaluación }\end{array}$ \\
\hline \multirow[t]{2}{*}{$\begin{array}{l}\text { Reforma e } \\
\text { implementación } \\
\text { 2003-2006 }\end{array}$} & $\begin{array}{l}\text { - Implementación y extensión de la cobertura, 2004- } \\
2006 \\
\text { - Monitoreo y diseminación de los avances }\end{array}$ \\
\hline & $\begin{array}{l}\text { - Evaluación externa del efecto de las políticas por } \\
\text { organizaciones internacionales y grupos académicos }\end{array}$ \\
\hline
\end{tabular}

cuestas son un testimonio sobre la solidez de la política informática en México bajo el liderazgo del Instituto Nacional de Estadística, Geografía e Informática, INEGI, y un instrumento clave para el análisis realizado por las instituciones de investigación de los diferentes sectores específicos, tales como el INSP.

Los resultados de este estudio -conocimientos, información, evidencias y personas entrenadas para llevar a cabo el análisis del gasto en salud-facilitaron el trabajo que alimentó a la reforma. También resultó de utilidad para producir el análisis sobre la justicia del financiamiento que se incluyó en el análisis del desempeño de los sistema de salud del Informe Mundial de Salud 2000 de la Organización Mundial de la Salud. ${ }^{9}$ Cuando se estaba elaborando el informe, México era uno de los pocos países en desarrollo que había emprendido este tipo de análisis a profundidad. De hecho, sólo unos cuantos países habían hecho un análisis a nivel nacional de las fuentes de financiamiento a través de las Cuentas Nacionales de Salud; entre ellos se cuenta Colombia, ${ }^{25}$ también sobre el tema de la reforma del sistema de salud. En consecuencia, el trabajo nacional alimentó la producción del conocimiento y de los marcos internacionales. ${ }^{26}$

La combinación del análisis nacional con el internacional catalizó la reforma. La clasificación de México en el Informe Mundial de Salud $2000^{9}$ resultó impactante. La desigualdad en el financiamiento y en la protección financiera endémica en el sistema mexicano de salud se tradujo en el sitio 144 en materia de justicia en el financiamiento, a diferencia de la clasificación general, en la cual ocupó el sitio 51 entre 191 países. Las comparaciones internacionales de las Cuentas Nacionales de Salud también hicieron posible vincular dos datos importantes: México estaba ofreciendo protección financiera a menos de la mitad de su población, como ocurre con muchos de los países de la región, pero además tenía niveles desproporcionadamente altos de gasto de bolsillo en salud (figura 1).

Esta información, más que generar una reacción defensiva, afortunadamente llegó en un momento en que los encargados de elaborar las políticas estaban en posición de utilizarla como herramienta para su diseño. El Informe Mundial de Salud 2000 se publicó apenas meses antes del cambio de administración y coincidió con el trabajo del equipo de transición.

Asimismo, este mal posicionamiento en justicia financiera, junto con el capital (tanto de investigadores como de datos) que se había estado construyendo desde la década de 1990 en México, también catalizó un mayor número de análisis a profundidad. Este trabajo también generó evidencias que demostraron ser prominentes para el debate político y útiles para influir en el desarrollo de la política pública y el programa. Específicamente, mostró que en el año 2000 entre dos y cuatro millones de hogares hicieron pagos a la atención médica categorizados como catastróficos y empobrecedores. ${ }^{21,27,28}$ Adicionalmente, se demostró que la incidencia de gastos tanto catastróficos como empobrecedores era mucho más alta entre los hogares pobres y no asegurados. Los no asegurados representan $86 \%$ de estas familias y la proporción del gasto empobrecedor y catastrófico en salud es más de cuatro veces superior. Además, el gasto en salud que conduce al empobrecimiento (ser empujado por debajo de la línea de pobreza) se concentra casi totalmente en los hogares del quintil más pobre de la distribución del in- 
greso, que son predominantemente no asegurados. ${ }^{27,28}$ Es de notar que las catástrofes financieras para muchos de estos hogares, resultantes de los gastos en salud, suelen no ser cuantiosas nominalmente y no incluyen las hospitalizaciones -en el caso de los más pobres, reflejan la incapacidad para financiar incluso los problemas de salud más comunes- (cuadro II y figura 2).

El análisis a profundidad, a nivel de país, continuó después de que la reforma fue aprobada y hecha ley, convirtiéndose en una útil herramienta de monitoreo. Desde 2001, la Secretaría de Salud ha publicado informes anuales, con datos comparativos, que incluyen información sobre la protección financiera y las tasas del gasto catastrófico y emprobrecedor en salud. A medida que ha evolucionado el trabajo analítico y los datos de las encuestas, los indicadores también lo han hecho, por lo que cada año se ha publicado más información de manera exhaustiva. ${ }^{20-22,29,30}$ Estos reportes son ampliamente difundidos a través de foros públicos y se encuentran disponibles en el sitio web de la Secretaría de Salud (www.salud.gob.mx).
Es importante notar que la investigación a nivel mundial facilitó ampliamente la profundización del análisis en México, incorporándolo en el Programa Nacional de Salud 2001-2006 y en los primeros reportes de análisis comparativo de desempeño. Las metodologías y el análisis entre países de la OMS 2000, que primeramente fueron presentados en documentos de trabjo y posteriormente como artículos publicados, ${ }^{31}$ fueron incorporadas y adaptadas para generar un análisis más específico de la reforma mexicana. ${ }^{27,28}$

Las evidencias también fueron una herramienta para el diseño de las políticas, particularmente para expandir la cobertura de las poblaciones y los servicios. En primer lugar, los resultados demostraron la importancia de ofrecer protección social a las familias más pobres -incluidas tanto las áreas rurales como las ciudades-. En segundo, y como lo ilustra la figura 2, mostraron la importancia de cubrir nominalmente los rubros de bajo costo, como la atención ambulatoria y los medicamentos. Estas cuestiones se incorporaron en el diseño de la reforma.

\section{Cuadro II \\ Cómo LA ENFERMEdAd SE CONVIERTE EN EMPOBRECIMIENTO: ESTUdIOS HIPOTÉTICOS DE CASO DE DOS FAMILIAS MEXICANAS}

Todo el financiamiento de los sistemas de salud proviene de los hogares, aunque a menudo es algo que olvidamos en el análisis. Como Fuchs lo ha señalado:

"El punto más básico, que con frecuencia no se expone claramente en las discusiones públicas, es que la gente debe pagar la atención bajo cualquier sistema de financiamiento... el costo final recae sobre las familias y las personas incluso cuando el mecanismo de pago haga parecer que la cuenta se le manda a alguien más." ${ }^{3}$

Mantener esto como una referencia para el análisis es importante para asegurar que las evidencias sean útiles en el diseño de las políticas. Para ilustrar esto, los siguientes casos de estudio están diseñados para describir situaciones que sufren muchas familias para enfrentar sus gastos de atención en salud.

Caso I: Para Ana Luisa, madre de dos hijos que vive en el poblado de San Bartolo Coyotepec en Oaxaca, dos infecciones comunes de garganta en sus niños generan un gasto catastrófico en salud. Similar a varios de los 1.7 millones de hogares cuyo jefe de familia es una mujer, ${ }^{2}$ la familia sobrevive con $\$ 57$ pesos $^{34}$ diarios, que Ana Luisa gana como peinadora en un salón de belleza de la Ciudad de Oaxaca. ${ }^{35}$ Cuando su hijo Eduardo se quejó de dolor de garganta y fiebre, ella perdió un día de trabajo para llevar a su hijo de 6 años al doctor. Además de perder su salario, Ana Luisa pagó $\$ 3.85$ dólares por la consulta debido a que llevó a su hijo a la clínica pediátrica, ya que no cuenta con Seguro Popular ni con alguna otra modalidad de seguro de salud. Si hubiera hecho una cita con un pediatra privado, hubiese pagado entre $\$ 16.60$ y $\$ 25$ dólares, pero el tiempo de espera hubiese sido menor y quizás habría perdido menos de un día completo de trabajo. La infección de garganta de Eduardo requiere comprar en la farmacia Amoxicilina, que cuesta entre $\$ 5.40$ y $\$ 7.90$ dólares, o penicilina, que cuesta $\$ 3.85$ dólares. También debe pagar los gastos de transporte y faltar al trabajo otro día para atender a Eduardo, o bien, pagarle a una vecina entre 8 y 12 dólares por cuidarlo dos días mientras ella trabaja hasta que el niño se recupere y pueda asistir a la escuela. Dos días después, el hijo menor de Ana Luisa, Pedro, se queja de síntomas similares. En vez de ir de nuevo al doctor y perder otro día de trabajo, Ana Luisa decide darle el mismo antibiótico y le da la misma dosis que a Eduardo.Afortunadamente, el antibiótico le funcionó a Pedro; sin embargo, si ella se hubiera equivocado, hubiese sido necesario pagar un tratamiento mucho más complicado y costoso.

A pesar de haber elegido el camino más económico de llevar a su hijo al hospital infantil y comprar la medicina más barata, Ana Luisa dejó de ganar $\$ 5.12$ dólares de su sueldo y gastó $\$ 13.44$ dólares en atención médica y medicinas, $\$ 2.69$ dólares en transporte y pagó $\$ 16$ dólares para que le cuidasen a sus hijos 4 días -más de 6 veces su sueldo diario-. Si hubiera llevado a los dos niños al médico privado y elegido el antibiótico más caro, hubiera gastado en total $\$ 70$ dólares, y hubiera faltado al trabajo de 2 a 4 días para cuidar a sus hijos. Esto asciende a más de $50 \%$ del ingreso familiar total, y probablemente a más de $30 \%$ de su ingreso disponible (excluidos los alimentos) durante un periodo de tres meses. Este caso ilustra la manera en que incluso los problemas simples y comunes de salud pueden ocasionar dificultades significativas para los millones de familias mexicanas que viven por debajo de la línea de pobreza. ${ }^{4}$

Caso 2: Elena vive en un área rural de Veracruz y se le diagnosticó diabetes tipo 2 hace dos años. Es representativa del porcentaje superior al $10.7 \%$ de la población entre 20 y 69 años de edad que tiene diabetes en México. ${ }^{36} \mathrm{Su}$ esposo trabaja como jornalero en el campo en Veracruz, para mantener a su esposa, sus cinco hijos y sus padres. Como ocurre con muchas familias rurales de México, usualmente gana menos de $\$ 300$ dólares al mes, ${ }^{37-38}$ lo que asciende a menos de un dólar diario per cápita. Los gastos médicos de un hogar en que uno de los miembros de la familia es diabético fácilmente ascienden a un promedio mensual superior a $\$ 100$ dólares para cubrir las consultas, medicamentos e insumos como las tiras reactivas para medir la glucemia, las tiras reactivas para orina y las jeringas para insulina. ${ }^{39} \mathrm{La}$ familia ya vendió sus dos vacas y su televisión para financiar su atención. Elena no está asegurada y no puede sufragar los costos adicionales que implica manejar su enfermedad crónica en forma continua. Por lo que ella no es constante con el auto-monitoreo y el uso de insulina $y$, en consecuencia, tiene riesgo de sufrir complicaciones serias. 


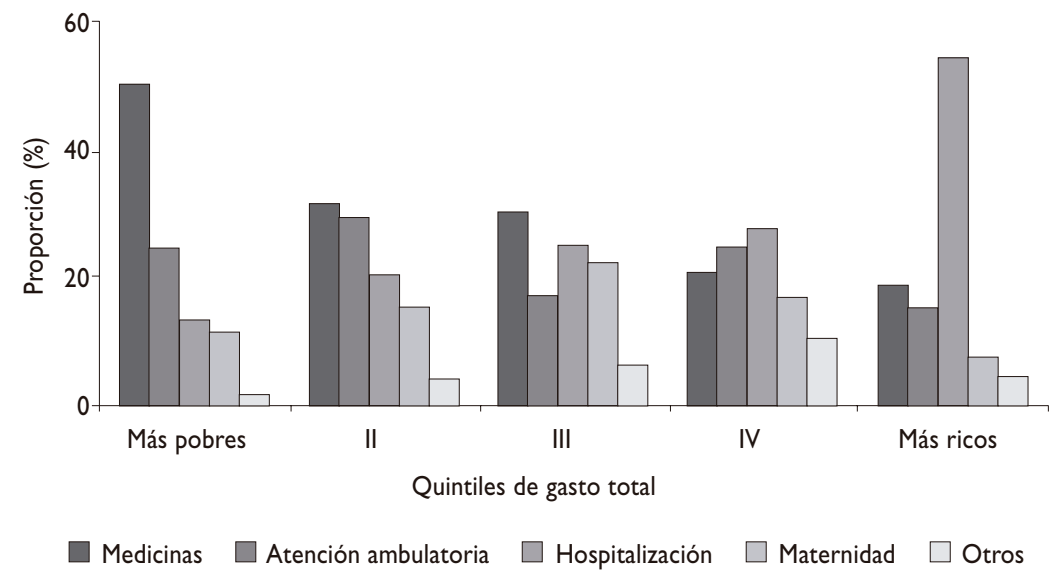

El análisis de las categorías de los gastos de salud que generan una catástrofe financiera y empobrecimiento coincide con los casos antes descritos (cuadro II). Entre las familias pobres, el gasto empobrecedor y catastrófico en salud se concentra en los medicamentos y la consulta médica ambulatoria. Entre las familias de más recursos se concentra en las hospitalizaciones.

Estos resultados son una lección importante que señala la necesidad de crear y diseñar protección social en salud dirigida a las familias pobres para prevenir el empobrecimiento derivado del gasto en salud.A diferencia del seguro de salud tradicional para cubrir las enfermedades catastróficas, estos programas deben incluir componentes de bajo costo nominal como los medicamentos y las consultas médicas para las enfermedades crónicas, así como de los problemas comunes en salud. ${ }^{27,28}$ Este hallazgo se incorporó dentro del diseño del Seguro Popular de Salud a través del paquete de servicios cubiertos y a través de la prioridad que se está otorgando al abasto y a la provisión de los medicamentos

Fuente: ENIGH, 2000

* Definido como gastos en salud de $30 \%$ o más del ingreso trimestral disponible

\section{Figura 2. Distribución del gasto en salud catastrófico,* por RUbro de los hogares y por QUiNTIL}

El reconocimiento de los riesgos financieros derivados del alto nivel del gasto de bolsillo fue, entre otros, uno de los pivotes para la definición de los aspectos técnicos de la reforma. Por esta razón, la reforma mexicana de la salud de 2003 constituye un ejemplo de un proceso exitoso de la combinación de la relevancia y la excelencia en la investigación a través de la aplicación de las evidencias de la investigación a la formulación de políticas y del avance de la investigación..$^{26,32}$ Las evidencias seguirán desempeñando un papel importante en todas las etapas futuras de la innovación, el seguimiento, la difusión y la promoción de la calidad.

\section{Evolución del gasto catastrófico y empobrecedor en salud y las brechas de pobreza: 1992-2004}

$\mathrm{Al}$ utilizar las definiciones de Knaul y colaboradores ${ }^{27}$ sobre los datos de gasto por hogar para la ENIGH, se encuentra que por trimestre $6.3 \%$ de los hogares mexicanos resultan afectados por gastos en salud catastróficos o empobrecedores (cuadro III). Este dato trimestral representa casi 1.5 millones de hogares. Si se utiliza un límite de 20\% del ingreso disponible para definir el gasto catastrófico, y sin incluir el empobrecimiento absoluto (los hogares que están por abajo, o caen por aba-

\section{Cuadro III Datos}

Las principales fuentes de datos para este estudio fueron las siete versiones de la Encuesta Nacional de Ingreso y Gasto de los Hogares (ENIGH) levantada cada dos años entre 1992 y 2004. El periodo abarca la crisis económica de 1994-1996 y la recuperación económica experimentada de mediados a fines de la década de 1990. También incluye la fase piloto del Seguro Popular de Salud (200I-2003) previa a la reforma y los dos primeros años de la introducción gradual del periodo de transición de siete años hacia la protección social universal en salud a través de la reforma en el sistema de salud.

La ENIGH es una encuesta a nivel hogar, transversal y representativa a nivel nacional, que es realizada por el Instituto Nacional de Estadística, Geografía e Informática (www.inegi.gob.mx). Contiene preguntas detalladas y estandarizadas sobre todas las fuentes de ingresos y gastos (incluido un módulo sobre salud) a nivel del hogar. La encuesta también incluye la composición familiar, y la situación de los mercados laboral y educativo. El marco temporal, la metodología y los cuestionarios son consistentes y comparables a través de los años. La base de datos incluye los años 1992, 1994, 1996, 1998, 2000, 2002 y 2004. ${ }^{2}$ Los detalles adicionales sobre la serie de la ENIGH y la manera en que dicha información se ha vuelto comparable a través de los años se presenta en Knaul y colaboradores, 2006. ${ }^{28}$

En el análisis de regresión presentado en el trabajo utilizamos la ENSANUT 2006. Esta encuesta se describe en Gakidou y colaboradores dentro de esta edición. ${ }^{6}$

Los datos sobre la cobertura del Seguro Popular provienen de la base de datos sobre afiliación, manejada por la Comisión Nacional de Protección Social. Estos datos ofrecen información trimestral sobre el número de familias y personas afiliadas al programa en cada municipio. Los datos disponibles al momento de escribir el presente estudio comprenden el periodo a partir del cuarto trimestre de 2002 y hasta el primer trimestre de 2006. 
jo de la línea de pobreza debido al gasto en salud), la cifra es de casi 2 millones de hogares por trimestre en el año 2000. Dado que no hay consenso sobre el umbral de gasto catastrófico, sobre la definición de empobrecimiento por debajo de la línea de pobreza ni sobre la anualización de las cifras, estas estimaciones del número de hogares afectados en un año se debe de contemplar sobre un amplio rango.

Estas consideraciones sobre la medición de GCES se discuten en detalle en Knaul y colaboradores. ${ }^{27}$ De cualquier modo, parece necesario realizar aún bastante trabajo en cada país y entre países para llegar a un consenso. Los indicadores miden distintos aspectos de cómo resultan afectadas las familias por el impacto de gasto en salud, y cada uno tiene mérito. Una de la principales preocupaciones es la periodicidad de los gastos en salud en relación con el nivel de pobreza de la familia, un punto que debe ser incorporado tanto en el numerador como en el denominador de los indicadores de gastos en salud empobrecedores y catastróficos en análisis futuros. Otro asunto importante es el de cómo incorporar a familias que dejan o no usan la atención porque no pueden pagarla. No es posible tratar aquí todos estos puntos por falta de datos longitudinales, pero se usan diversas mediciones de catástrofe y empobrecimiento para demostrar la solidez de las tendencias y hallazgos.

Como se documentó anteriormente, todos los indicadores de protección financiera -gasto catastrófico y empobrecimiento absoluto (cuadro IV)- muestran un deterioro durante el periodo de crisis económica y una mejoría continua, posterior a la crisis, de 2000 a $2004.27,28$

\section{Cuadro IV \\ INDICADORES}

Las tendencias de la carga que representa el gasto en salud sobre los hogares a lo largo del periodo 1992 a 2004 se resumen utilizando diversos indicadores: $:^{27,28,40} \mathrm{I}$ ) La proporción de hogares con gastos catastróficos en salud, medidos como el gasto superior a una proporción específica del ingreso disponible (ingreso total menos el gasto en necesidades básicas aproximado por el gasto en alimentos) siguiendo la metodología de la OMS (2000) y de Murray, Knaul, Xu et al., que incluye una estimación de todas las fuentes del gasto en salud (tanto del bolsillo como prepagos). ${ }^{10,31} 2$ 2) La proporción de los hogares con gastos empobrecedores en salud, los cuales se definen como la caída por debajo de la línea de pobreza absoluta, o la profundización del nivel de pobreza en el caso de quienes ya se encuentran por debajo de la línea de pobreza. 3) La proporción de familias con un gasto en salud "excesivo", definido como el evento de sufrir un gasto catastrófico o empobrecedor en salud o ambos $y$, por ende, toma en cuenta los aspectos tanto absolutos como relativos de la carga del gasto en salud. Se analizan además los hogares que fueron empujados por debajo de la línea de pobreza debido al gasto en salud, lo cual es un subcomponente del indicador de incidencia de la pobreza.
Los cambios más notorios ocurren en la proporción de los hogares con gastos empobrecedores en salud.

Estos resultados son consistentes pero especialmente sensibles a las tendencias del empobrecimiento absoluto, lo que a su vez es sensible a la línea de pobreza y al análisis del gasto de las familias que viven por debajo de la línea de pobreza.

Para un mejor análisis, se presentan las tendencias del gasto empobrecedor y catastrófico por separado y usando cuatro líneas de pobreza para el empobrecimiento (cuadro $\mathrm{V}$ ) y un punto de corte adicional de $20 \%$ para el gasto catastrófico (figura 3). A pesar de que las tendencias difieren sustancialmente en el nivel y, hasta cierto punto, por año, y no todas las diferencias entre los años son estadísticamente significativas, el resultado es consistente: un deterioro alrededor de la crisis económica y una mejoría desde 1998-2000 hasta 2004.

También se estudió, mediante el uso de cinco líneas de pobreza (cuadro V), un fenómeno mucho menos común: el número y la proporción de familias que están por debajo de una determinada línea de pobreza debido al gasto en salud (conteo de la pobreza). Las dos líneas de pobreza de un dólar siguen la misma tendencia descendente. Para las demás líneas de pobreza no existe una tendencia clara, aunque hay una mejoría entre 2000 y 2002 (figura 4).

Con el fin de agregar claridad a estos resultados, se estudió la brecha de pobreza (cuadro VI, VII y VIII), ${ }^{43}$ la cual se refiere a la manera en que el gasto en salud profundiza la pobreza al empujar a las familias:

- Que ya están por debajo de la línea de pobreza, todavía más abajo, y la magnitud del descenso, o

- Por debajo de la línea de pobreza, y la magnitud del descenso.

Utilizamos la línea de pobreza de dos dólares en PPA (paridad del poder adquisitivo), dado que su tendencia es ambigua y representa una prueba más

\section{Cuadro V \\ LÍNEAS DE POBREZA}

Los indicadores se analizan utilizando diferentes líneas de pobreza que se establecieron para los años sobre los cuales se dispone de datos (1992, 1994, 1996, 1998, 2000, 2002 y 2004). La información fue ajustada según el poder adquisitivo en cada uno de los años, para lo cual se hizo uso del Indice de Paridad del Poder Adquisitivo (PPA) de la Organización de Cooperación y Desarrollo Económico (OCDE). ${ }^{41}$ Se analizaron cinco líneas de pobreza: \$I dólar americano per cápita al día, $\$$ I dólar por persona al día en PPA, $\$ 2$ dólares americanos al día per cápita, $\$ 2$ dólares por persona al día en PPA, y la línea de pobreza alimentaria (basada en SEDESOL y disponible solamente para 2000-2004). ${ }^{42}$ 

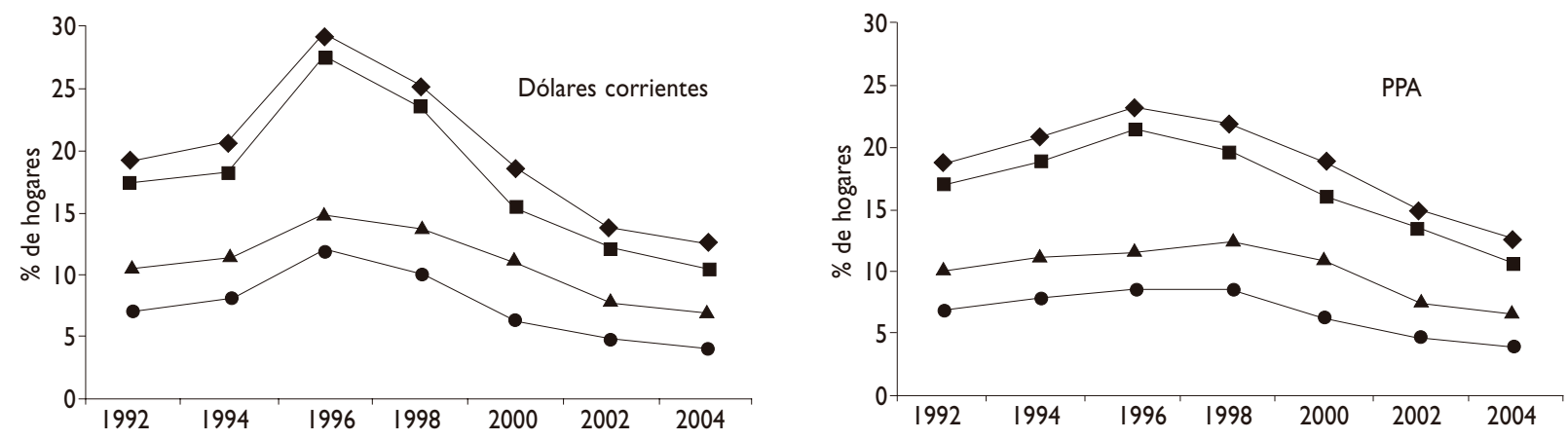

Línea de pobreza (LP) y puntos de corte del gasto catastrófico en salud (\% del ingreso disponible)

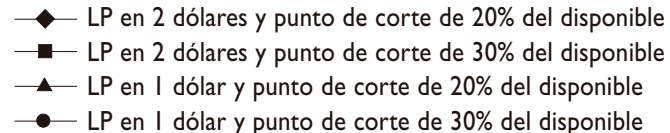

Figura 3. Gasto catastrófico y empobrecedor en SALUd Con VARiaciones en La Línea de Pobreza y PUNTOS DE CORTE EN EL UMBRAL CATASTRÓFICO, DÓLARES CORRIENTES CONTRA PARIDAD DE PODER ADQUISITIVO

estricta de una mejoría durante el periodo de la reforma (cuadro VII y VIII). Los resultados muestran que cada año el gasto en salud profundiza la pobreza. A su vez, en 1994 comparado con 1992, 1994 comparado con 1996 y en 1998 comparado con 1994, la contribución del gasto en salud a la profundización de la pobreza fue significativamente mayor. En contraste, lo opuesto se aplica a 2002 en relación con 2000 y a 2004 en relación con 2002. En otras palabras, el gasto en salud contribuye ahora en menor medida al grado en que las familias están por debajo de la línea de pobreza. Las diferencias entre periodos muestran que la mejoría (reducción) en la profundización de la pobreza derivada del gasto en salud fue mayor entre 2002 y 2004 en comparación con los demás periodos, con excepción de 2000 a 2002. Estos resultados son robustos a cambios en la línea de pobreza.

Este resultado también es evidente cuando se analiza la evolución del GCES entre las familias con y sin acceso a la seguridad social. ${ }^{27,28}$ El deterioro durante el periodo de crisis afectó a ambos grupos. En contraste, las mejorías entre 2000 y 2004 se concentran entre los hogares que no tienen acceso a la seguridad social y que no están asegurados o tienen SPS. Las mejorías también se concentran en el quintil más pobre. En el mismo periodo y para el resto de la población hay pocos cambios. Aún más, aunque hubo una mejoría para todas las familias en el período poscrisis, esta es más evidente para aquellas con hijos. Las mejorías fueron menos marcadas entre las familias con adultos mayores en las que

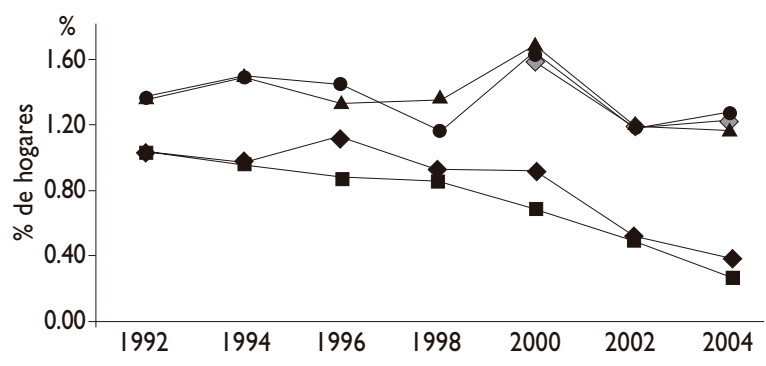

Línea de pobreza

— En I dólar corriente

- En I dólar PPA

—-En 2 dólares corrientes

- En 2 dólares PPA

$\prec$ Alimentaria

Fuente: Estimaciones propias de los autores con datos de la ENIGH 1992 a 2004 y SEDESOL $(2005)^{38}$

Figura 4. Hogares que caen bajo la línea de pobreza AL CONTABILIZAR SU GASTO EN SALUD

hay una mayor probabilidad de que los gastos catastróficos en salud sean los más elevados.

Todos los resultados hasta este momento son consistentes con cuando menos dos explicaciones posibles e interrelacionadas: las reducciones de la pobreza, y la expansión de la protección financiera en salud a través del SPS. Durante el periodo examinado en este estudio, ini- 


\section{Cuadro VI}

BRECHA DE POBREZA

Con base en la metodología propuesta por estudios de varios países asiáticos se buscó determinar el impacto del gasto en salud sobre el empobrecimiento. ${ }^{12,43}$ Esto implicó considerar tanto a los hogares que fueron empujados por debajo de la línea de pobreza debido al gasto en salud, como a los hogares que ya se encontraban por debajo de dicha línea y que se empobrecieron aún más por el gasto en salud. La metodología de Wagstaff y Van Doorslaer ${ }^{43}$ permite analizar en qué magnitud se encuentran por debajo de la línea de pobreza, así como la magnitud de esta cantidad con respecto a la pobreza total. Básicamente, la brecha de pobreza puede definirse como el valor promedio en pesos que un hogar por debajo de la línea de pobreza necesita para alcanzar la línea. Este ejercicio se realiza antes y después del gasto en salud y después se comparan ambos resultados. Cada paso de proceso para el análisis de la ENIGH 1992-2004 se describe en los cuadros VII y VIII y es acorde con Wagstaff y Van Doorslaer. ${ }^{43}$

Este análisis es sensible a la selección de la línea de pobreza. Por esta razón, se reproduce el estudio para cada una de las cinco líneas de pobreza descritas en cuadroV. Para el texto, se decidió utilizar la línea de pobreza de dos dólares en PPA, con el fin de aplicar la prueba más difícil a la pregunta de interés. La pregunta clave es saber si la brecha de pobreza, resultante del gasto en salud, declinó durante el periodo del Seguro Popu- lar de Salud. Los hallazgos son bastante sólidos a cambios en la línea de pobreza.

Dado que se cuenta con una serie temporal larga, se puede comparar no sólo la brecha de pobreza antes y después del gasto en salud, sino también la diferencia en la brecha año tras año y los cambios en la brecha a través de periodos de tiempo. Se consideró a la diferencia en la pobreza antes y después del gasto en salud como el grado en el cual el gasto en salud profundiza la pobreza. La diferencia entre periodos de tiempo permitió determinar si la profundización de la pobreza, debido al gasto en salud, fue mayor o menor en un periodo versus otro.

Adicionalmente, la diferencia entre periodos de tiempo permite comparar el momento de implantación del Seguro Popular de Salud con periodos anteriores. También permite contextualizar o determinar el efecto neto de la crisis económica de 1994-1996. A cada diferencia se le hacen las pruebas de significancia estadística del cambio utilizando los factores de expansión de las encuestas.

Todo el análisis se realizó haciendo uso del software estadístico Stata 8 y la significancia estadística de cada diferencia se programó manualmente para poder incorporar los factores de expansión específicos a cada población.

\section{Cuadro VII \\ Brecha de Pobreza ANTES Y DESPUÉs DEL GASTO EN SALUd, 1992-2004*}

\begin{tabular}{|c|c|c|c|c|c|c|c|}
\hline & \multicolumn{7}{|c|}{ Año } \\
\hline & 1992 & 1994 & 1996 & 1998 & 2000 & 2002 & 2004 \\
\hline \multicolumn{8}{|l|}{ Brecha de pobreza } \\
\hline Con respecto a la línea de pobreza antes del gasto en salud & -177.88 & -197.11 & -387.63 & -437.94 & -383.40 & -352.26 & -263.51 \\
\hline Con respecto a la línea de pobreza posterior al gasto en salud & -185.36 & -206.55 & -403.26 & -456.60 & -406.36 & -370.26 & -278.39 \\
\hline \multicolumn{8}{|l|}{ Posterior al gasto en salud vs antes del gasto en salud } \\
\hline Impacto en la brecha de pobreza del gasto de bolsillo en salud & $-7.47^{\ddagger}$ & $-9.44^{\ddagger}$ & $-15.64^{\ddagger}$ & $-18.66^{\ddagger}$ & $-22.96^{\ddagger}$ & $-18.00 \ddagger$ & $-14.88^{\ddagger}$ \\
\hline
\end{tabular}

cialmente la pobreza aumentó y después se declinó. La proporción de hogares que viven con menos de 2 dólares al día ha declinado continuamente entre 1998 y 2004 desde más del $25 \%$ hasta casi el $15 \%$. Esto probablemente se debe a una combinación de políticas macroeconómicas, los programas de reducción de la pobreza como Oportunidades, ${ }^{42}$ y otros programas sociales como el SPS. En ausencia de información longitudinal y de una evaluación formal es imposible determinar el papel causal y relativo de cada factor. De cualquier manera, los resultados de la regresión ofrecen evidencias que sugieren una asociación del SPS y el GCES que va más allá de los cambios en la pobreza.

El análisis de regresión utilizando los datos de la ENSANUT (cuadro IX, X y XI) sugiere una asociación negativa entre tanto el gasto catastrófico como el gasto de bolsillo, y la cobertura del SPS.Además, los resultados se mantienen firmes ante diferentes especificaciones de las variables independientes y dependientes. De particular importancia es que los resultados son significativos incluso cuando se introducen a la regresión variables que controlan por el nivel de pobreza del municipio y de la familia.

Deben hacerse varias advertencias al interpretar los resultados de la regresión en materia de la relación entre la cobertura del SPS y el GCES. Estos resultados no son causales, sino descriptivos, dado que no se cuenta con datos longitudinales ni variables instrumentales efectivas. Debido a que no se dispone de variables instrumentales, las regresiones del gasto de bolsillo por 


\title{
Cuadro VIII \\ Diferencias entre periodos de tiempo en la brecha de pobreza antes y después del gasto en SALUd*
}

\author{
Diferencia
}

Diferencias entre años consecutivos

\begin{tabular}{ll}
$1992-1994$ & $-1.96^{\ddagger}$ \\
$1994-1996$ & $-6.20^{\ddagger}$ \\
\hline $1996-1998$ & $-3.02^{\ddagger}$ \\
\hline $1998-2000$ & -4.30 \\
\hline $2000-2002$ & $4.96^{\ddagger}$ \\
\hline $2002-2004$ & $3.12^{\ddagger}$
\end{tabular}

Diferencias entre periodos de tiempo

$(1998-2000)-(2000-2002)$

$\begin{array}{ll}(1998-2000)-(2002-2004) & 7.43\end{array}$

(2000-2002) - (2002-2004) $\quad-1.84^{\ddagger}$

(1992-1994) - (2002-2004) $5.09 \ddagger$

(1992-1998) - (2002-2004) |4.3|‡

* Línea de pobreza definida como \$US 2 (en PPA) al día per cápita

₹ Diferencias significativas con un nivel de confianza de $90 \%$

Fuente: Estimaciones propias de los autores usando la ENIGH (Encuesta Nacional de Ingresos y Gastos de los Hogares)

\section{Cuadro IX \\ ANÁLISIS DE REGRESIÓN DE LOS DATOS DE LA ENSANUT}

Los datos de la ENSANUT aunque son transversales, tienen dos ventajas importantes. En primer lugar, abarcan un periodo en que el Seguro Popular de Salud ya estaba operando en muchas áreas del país y cubría un número considerable de familias (2005-2006). En segundo lugar, estos datos incluyen muchas preguntas sobre el gasto en salud, lo que posibilita medir el gasto total en salud de diversas maneras.

Con el fin de aprovechar dichas ventajas, se llevó a cabo un análisis de regresión utilizando tres diferentes medidas del gasto en salud y tres medidas diferentes del ingreso disponible para un total de nueve medidas.

Los denominadores de la capacidad de pago (ingreso disponible) son los siguientes:

I) La capacidad de pago (CDP) se define como el gasto total (GT) menos la línea de pobreza alimentaria (LPA), en donde el GT se calcula con todas las preguntas que no se refieren al gasto en salud extrapoladas al gasto anual más el gasto en salud (GS). La LPA se calcula como el gasto promedio en alimentos de los hogares cuya participación de los alimentos (proporción que representan el gasto en alimentación respecto al gasto total) cae entre los percentiles $45^{\circ}$ y $55^{\circ}$. Esta medida de la pobreza se usa para definir la CDP para evitar bajar artificial- mente la CDP de los hogares más ricos que gastan en alimentos más de lo necesario para subsistir. En seguida se ajusta la LPA con base en el tamaño del hogar.

2) Cuando la LPA es mayor que el GT de un hogar, se sustituyó el gasto real del hogar en alimentos por la LPA.

3) Se redefinió la CDP como el GT menos el gasto en alimentos cuando la LPA es mayor que el gasto del hogar en alimentos.

Para el gasto en salud se extrapoló cada pregunta sobre gasto a valores anuales y se definieron tres maneras diferentes de medir el gasto en salud por hogar, como se presenta a continuación:

I) El gasto en hospitalización en el último año, más el gasto en consulta ambulatoria, dentista, medicamentos y otras preguntas sobre GS trimestral.

2) Preguntas trimestrales sobre hospitalización $y$ todas las preguntas trimestrales sobre GS mencionadas anteriormente.

3) A partir de las preguntas sobre el gasto anual en salud proveniente del ingreso corriente, ahorros, venta de bienes, y préstamos de dinero. sí mismas no controlan el sesgo de selección que probablemente afecte significativamente la magnitud del coeficiente del SPS.

Escogimos los datos de la ENSANUT, aunque son transversales, porque cubren un periodo más largo del SPS y son considerados, por lo tanto, más confiables para esta parte del análisis. Se hará trabajo de seguimiento a partir de las siguientes rondas de la dicha encuesta como parte de la evaluación aleatoria del SPS que se está llevando a cabo. ${ }^{17}$ También se está emprendiendo trabajo econométrico sobre los datos transversales de la serie del tiempo de la ENIGH. Estas encuestas serán aprovechadas con mayor profundidad mediante técnicas econométricas de mayor sofisticación (basadas en el pareo) 
Cuadro X

Definiciones de las nUeVe medidas utilizadas para estimar el gasto catastrófico con la ENSANUT

\begin{tabular}{lcl} 
Línea de pobreza alimentaria > gasto total & Medida catastrófica & $\begin{array}{c}\text { Definición de gasto en salud } \\
\text { Costo de hospitalizaciones del año anterior y otras } \\
\text { preguntas sobre el gasto trimestral en salud }\end{array}$ \\
\hline & 2 & $\begin{array}{l}\text { Costo de hospitalizaciones en los últimos tres meses y } \\
\text { otras preguntas sobre el gasto trimestral en salud }\end{array}$ \\
\hline 3 & $\begin{array}{l}\text { Dinero gastado en salud proveniente de ingresos, } \\
\text { ahorros, venta de bienes,y préstamos }\end{array}$
\end{tabular}

\begin{tabular}{lll} 
Línea de pobreza alimentaria > gasto del hogar en alimentos & 4 & Igual que I \\
\hline & 5 & Igual que 2 \\
\hline 6 & Igual que 3
\end{tabular}

\begin{tabular}{lll} 
Capacidad de pago (CDP) es siempre el gasto total - gasto del hogar en alimentos & 7 & Igual que I \\
\hline 8 & Igual que 2 \\
\hline & 9 & Igual que 3
\end{tabular}

En el texto se presentan resultados para las definiciones 7,8 y 9 porque estos son los más similares a las medidas que se tienen con los datos de la ENIGH. Como se observa en el texto, los resultados son altamente consistentes a través de todas las regresiones de la ENSANUT y por lo tanto robustos ante diferentes medidas de gasto en salud. La construcción de quintiles de ingreso permanente se describe en Gakidou y colaboradores ${ }^{6}$

en estudios futuros y una vez que esté disponible la serie completa de datos incluyendo la ENIGH 2005.

\section{Relevancia a nivel mundial de las lecciones aprendidas de la experiencia mexicana}

\section{Relevancia específica para las evidencias}

La experiencia mexicana de abordar el problema del GCES proporciona varias lecciones sobre el aumento de la probabilidad de incorporar exitosamente las evidencias a la formulación de políticas para mejorar los sistemas de salud. ${ }^{16,26,32}$ Muchos de estos problemas no son específicos del sector salud, sino que más bien se aplican en forma más general a la formulación de las políticas, particularmente las del sector social.

La primera lección es crear una capacidad de investigación local para estimular los vínculos entre la investigación y las políticas. Un elemento clave detrás de la vinculación entre las evidencias y las políticas en la reforma mexicana de la salud fue la sólida base institucional de investigación. Esto sugiere la importancia que tiene para los países en desarrollo la inversión en la capacidad nacional de investigación -en instituciones públicas y privadas, y en las personas-. En el caso mexicano, muchos de los formuladores clave de las políticas durante la administración 2000-2006 habían sido líderes en el desarrollo de las instituciones locales de investigación. Los países que invierten en capacitar a los investigadores sobre cómo aplicar las evidencias a la formulación de las políticas, que producen los datos re- queridos para generar estas evidencias, y que apoyan a las instituciones de investigación y capacitación, tienen mayor probabilidad de tener encargados de elaborar políticas capacitados para aplicar las evidencias y que éstos estén abiertos a vincular estas evidencias con las políticas.

La segunda lección consiste en recabar datos y garantizar que éstos sean comparables a través del tiempo. Un ingrediente clave del trabajo de investigación que se ha realizado desde la década de 1990 sobre el financiamiento de la salud en México ha sido la disponibilidad de datos demográficos, epidemiológicos y económicos de buena calidad, particularmente sobre el gasto en salud. El conocimiento que han proporcionado esos datos también ha contribuido a recabar mejor información por medio de nuevas encuestas.

La tercera lección es invertir en investigación y participar en iniciativas y redes internacionales de investigación. El proceso de formulación de políticas generalmente incluye pocos incentivos y poco tiempo para la investigación y la publicación. En el caso mexicano, se ha puesto especial énfasis en promover la producción y la publicación de evidencias. El Foro Mundial para la Investigación en Salud (2004) y esta serie en sí mismos son ejemplos muy importantes de lo que se está logrando. Otra iniciativa importante en la que México está participando es en el (Health Financing Task Force: http:/ / www.healthfinancingtasktome.org/). Los ingredientes clave para que este esfuerzo sea exitoso son la búsqueda de canales efectivos para la publicación, tanto en el idioma local como en revistas internaciona- 


\section{Determinantes de la probabilidad de sufrir gastos catastróficos en SALUd (ENSANUT 2006)

\begin{tabular}{l}
$\begin{array}{l}\text { Gasto en salud }>20 \% \\
\text { del ingreso disponible }\end{array}$ \\
\hline I III
\end{tabular}

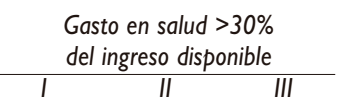

Cobertura del aseguramiento en salud (relativo a no asegurados)

\begin{tabular}{|c|c|c|c|c|c|c|}
\hline Seguro Popular & $-0.173^{*}$ & $-0.155^{*}$ & $-0.184^{\ddagger}$ & $-0.141 \ddagger$ & $-0.167^{\ddagger}$ & $-0.306 *$ \\
\hline Privado & $-0.549 \ddagger$ & $-0.543^{\ddagger}$ & -0.480 & $-1.253^{\S}$ & $-1.236^{\S}$ & -1.261 \\
\hline Seguridad Social & $-0.476^{\S}$ & $-0.469 \S$ & $-0.570^{\S}$ & $-0.476^{\S}$ & $-0.453^{\S}$ & $-0.539 \S$ \\
\hline
\end{tabular}

Ingreso permanente (relativo al quintil más pobre) ${ }^{4}$

\begin{tabular}{lcccccc} 
2o. Quintil & 0.063 & 0.092 & -0.019 & 0.065 & 0.085 & -0.093 \\
\hline 3er. Quintil & 0.047 & 0.091 & -0.158 & -0.053 & 0.118 & $-0.299^{\ddagger}$ \\
\hline 4o. Quintil & 0.085 & 0.102 & -0.174 & -0.022 & 0.005 & $-0.268^{\ddagger}$ \\
\hline 5o. Quintil (más rico) & -0.158 & -0.152 & $-0.345^{*}$ & -0.175 & -0.176 & $-0.530^{\S}$ \\
& & & & & & \\
Jefe del hogar mujer & 0.063 & $0.104^{\ddagger}$ & -0.071 & -0.020 & 0.077 & -0.086 \\
\hline Tamaño del hogar & $-0.042^{\S}$ & $-0.038^{*}$ & $-0.061^{\S}$ & $-0.087^{\S}$ & $-0.076^{\S}$ & -0.035
\end{tabular}

Edad del jefe del hogar (relativo a $<30$ años)

\begin{tabular}{lllllllll}
$30-39$ & 0.006 & 0.010 & 0.068 & 0.152 & 0.073 & 0.037 \\
\hline $40-49$ & 0.042 & 0.063 & 0.188 & $0.294^{*}$ & $0.246^{\ddagger}$ & 0.214 \\
\hline $50-59$ & $0.330^{\S}$ & $0.353^{\S}$ & $0.316^{*}$ & $0.556^{\S}$ & $0.50 I^{\S}$ & $0.430^{*}$ \\
\hline $60-69$ & $0.386^{\S}$ & $0.440^{\S}$ & $0.293^{\ddagger}$ & $0.638^{\S}$ & $0.637^{\S}$ & $0.487^{*}$ \\
\hline $70+$ & $0.473^{\S}$ & $0.509^{\S}$ & $0.447^{*}$ & $0.806^{\S}$ & $0.794^{\S}$ & $0.63 I^{*}$
\end{tabular}

Educación del jefe del hogar (relativa a sin educación)

\begin{tabular}{lrrrrrrr} 
Primaria & 0.023 & 0.025 & 0.000 & 0.013 & -0.013 & -0.020 \\
\hline Secundaria & -0.023 & 0.018 & -0.173 & -0.022 & 0.025 & -0.223 \\
\hline Más que secundaria & 0.067 & 0.122 & -0.009 & -0.015 & 0.002 & 0.068
\end{tabular}

Lugar de residencia (relativo a rural)

\begin{tabular}{lllllll} 
Urbano & -0.014 & -0.004 & -0.003 & -0.061 & -0.045 & -0.047 \\
\hline Metropolitano & $-0.154^{\ddagger}$ & -0.124 & $-0.382^{\S}$ & $-0.253^{*}$ & $-0.212^{*}$ & $-0.357^{*}$
\end{tabular}

\begin{tabular}{|c|c|c|c|c|c|c|}
\hline Presencia de niños $<5$ años en el hogar & $0.272^{\S}$ & $0.254^{\S}$ & $0.378^{\S}$ & $0.346^{\S}$ & $0.340^{\S}$ & $0.273^{*}$ \\
\hline Presencia de adultos $\geq 65$ años en el hogar & $0.321^{\S}$ & $0.310^{\S}$ & $0.325^{\S}$ & $0.273 *$ & $0.232^{\ddagger}$ & $0.379 *$ \\
\hline Indice de marginación municipal & $0.002^{\S}$ & $0.002^{\S}$ & $0.001 \ddagger$ & $0.002^{\S}$ & $0.003^{\S}$ & $0.002^{\ddagger}$ \\
\hline Constante & $-2.023^{\S}$ & $-2.222^{\S}$ & $-2.323^{\S}$ & $-2.521^{\S}$ & $-2.667^{\S}$ & $-2.965^{\S}$ \\
\hline
\end{tabular}

Tamaño de muestra $\quad 43214 \quad 43214 \quad 43214 \quad 4 \quad 43214$

$* p<0.0$ I
$\ddagger p<0.05$
$\S p<0.00$ I
I Costo de la estancia hospitalaria en el último año y otras cuestiones trimestrales relacionadas con el gasto en salud
II Costo de la estancia hospitalaria en los últimos tres meses y otras cuestiones trimestrales relacionadas con el gasto en salud
III Ingreso por salario, ahorro, venta de bienes y préstamos dedicado a gastos en salud

Fuente: Estimaciones propias de los autores basadas en la ENSANUT

Consultar http://www.funsalud.org.mx/competitividad.htm para una explicación y definición de las variables independientes 
les; la participación en redes internacionales de investigación y proyectos comparativos de alcance regional y global:;4 ${ }^{44}$ la vinculación entre los investigadores y las instituciones de investigación, tanto nacionales como internacionales; la disponibilidad de tiempo y oportunidades para que los encargados de elaborar políticas del más alto nivel escriban sus experiencias y las publiquen; y participar, tanto en calidad de anfitriones como de asistentes, en seminarios y congresos internacionales. El otro lado de la moneda para lograr el éxito de estos esfuerzos es que las revistas e instituciones internacionales ofrezcan opciones apropiadas para que los encargados de elaborar políticas, particularmente los de los países en desarrollo, publiquen su trabajo. Esto requiere de reglas académicas estrictas y explícitas sobre la publicación, pero también de la búsqueda de esquemas menos restrictivos que los que se aplican para artículos de investigación primaria.

La cuarta lección es que tanto los investigadores como los encargados de elaborar políticas deben esforzarse de manera especial por traducir los resultados de las investigaciones en mensajes y recomendaciones en materia de políticas. Esto requiere un intercambio continuo, el apoyo institucional a la investigación orientada a las políticas y una etapa adicional dentro del proceso de investigación: el desarrollo de resultados orientados a políticas, de tal manera que puedan ser más fácilmente difundidos por los encargados de elaborar políticas. Es importante que se haga una amplia difusión, no sólo entre legisladores y funcionarios, sino hacia el público en general, y particularmente a organizaciones de la sociedad civil y grupos de interés. Quizás el mejor ejemplo de esto en México es el indicador sobre el número de familias que sufren gastos catastróficos y empobrecedores en salud. La cifra anualizada del número de familias que sufren GCES en México, aunque difícil de cuantificar exactamente, se presenta de una manera científicamente defendible y que, al mismo tiempo, permite difundirla para influir sobre las políticas.

La quinta lección es la importancia de la oportunidad, la colaboración y la objetividad en la integración de marcos y evidencias internacionales elaborados por dependencias internacionales. Esta coincidencia en términos de tiempos entre el Informe Mundial de Salud 2000 y el cambio de gobierno en México proporcionó un ambiente propicio para que los hallazgos -y las críticas- se utilizaran como catalizadores del cambio e instrumentos para el desarrollo de nuevas políticas y programas. Contar con evidencia nacional, herramientas de investigación, datos y un grupo de investigadores hizo posible profundizar el análisis amplio, global, dentro del contexto nacional para su aplicación a la formulación de políticas en México.
Finalmente, en el caso mexicano fue muy útil vincular la investigación en el campo de las ciencias médicas y de la salud con la economía y la política económica y enfatizar los lazos entre la salud y la economía en la formulación de las políticas de salud. De nuevo, esto incluyó un esfuerzo explícito por aplicar los marcos internacionales como la Comisión de Macroeconomía y Salud. ${ }^{45-47}$ El resultado ha sido una poderosa herramienta para los encargados de elaborar políticas de salud para convencer a sus contrapartes del área económica del papel vital que juegan la salud y el sector salud en el desarrollo tanto económico como social.

\section{Relevancia específica para las políticas}

Este artículo analiza dos temas que tienen que ver con el gasto en salud catastrófico y empobrecedor y su relación con la reforma. En primer lugar, tomamos la forma en que México convirtió la evidencia sobre el déficit en protección financiera (y en consecuencia las altas tasas de gasto en salud catastrófico y empobrecedor) en un catalizador para la renovación institucional a través de la reforma en salud y la puesta en marcha del Seguro Popular de Salud. Enseguida examinamos uno de los resultados esperados más importantes: la reducción en la carga del gasto de bolsillo entre familias que no habían estado aseguradas y, por lo tanto, en la incidencia de gasto catastrófico y empobrecedor, particularmente en la pobreza.

La experiencia mexicana muestra que existe una relación entre la protección financiera en salud y el desempeño económico. La protección financiera en salud puede servir como red de seguridad para las familias ante las crisis económicas. El número de familias con GCES aumentó sustancialmente durante la crisis económica y esto probablemente hubiera sido menos pronunciado si esas familias hubieran tenido la cobertura de un seguro de salud. Los períodos económicamente desfavorables tienden a asociarse con la pérdida de empleos en el sector formal y esto, a su vez, significa la pérdida de la seguridad social y, por ende, de la protección financiera en salud. Además, típicamente se da un aumento de la pobreza y, en consecuencia se reduce la capacidad para financiar la atención médica. El seguro de salud puede cumplir la doble función de proteger a las familias contra las crisis de salud que aumentan las necesidades de atención médica, y contra las crisis económicas que reducen su capacidad para financiar la atención médica. La protección financiera en salud ayuda a garantizar que la enfermedad no obligue a las familias a elegir entre la ruina económica y la salud, y a que las crisis de salud temporales no se conviertan en un empobrecimiento permanente. 
El gasto en salud constituye una fuente adicional de pobreza, además del empobrecimiento ocasionado por la enfermedad misma. Es importante que los países empiecen a considerar el empobrecimiento adicional -en términos tanto del impacto sobre grupos específicos de familias como del nivel general de pobreza- ocasionado por el gasto en salud. La experiencia mexicana demuestra la importancia de reconocer esta realidad e incorporarla dentro del diseño de los programas del seguro de salud para garantizar que tanto los ricos como los pobres estén protegidos del GCES. Esto ha significado incorporar un diseño de seguridad social que difiere sustancialmente de los modelos tradicionales de aseguramiento de la atención médica. El modelo mexicano busca cubrir los riesgos que enfrentan los pobres y que incluyen rubros de bajo costo como los medicamentos y la atención ambulatoria. También busca cubrir a individuos y familias que tienen dificultades para participar de la seguridad social asociada con el mercado de trabajo formal, tales como los discapacitados, los desempleados, los migrantes y los hogares encabezados por mujeres.

Las evidencias también señalan la importante simbiosis y el reforzamiento mutuo que puede haber entre el seguro de salud y los programas sociales integrados, como Oportunidades. En el caso de México, y como se expone en Frenk, ${ }^{16}$ ésta fue una estrategia deliberada que ayudó a garantizar el éxito del SPS, dado que Oportunidades ya existía e incluía 5 millones de familias, la mayoría de las cuales no estaban aseguradas. Además del componente del diseño del programa, está claro que las familias pobres son más vulnerables y tienen mayor riesgo de GCES. Por ende, los programas sociales de prevención de la pobreza también pueden ayudar a evitar el GCES y viceversa.

Finalmente, los hallazgos presentados en este trabajo y en otras investigaciones realizadas sobre el GCES en México aluden a un importante desafío que México enfrentará en el futuro a medida que continúen la transición epidemiológica y el proceso de envejecimiento. Las evidencias presentadas en este trabajo sugieren que varios componentes clave del SP -asegurar a los quintiles más pobres, cubrir los medicamentos y la atención ambulatoria e incluir un paquete de gastos catastróficos- son estrategias efectivas para combatir el GCES. Las evidencias también sugieren que las familias en las que hay adultos mayores son particularmente vulnerables al GCES. ${ }^{48}$ Aunque este sector de la población aún no es muy grande, crece rápidamente. A medida que prosiga la reforma, será necesario cubrir a esas familias y expandir continuamente el paquete para incluir intervenciones de mayor costo. El envejecimiento de la población está avanzando rápi- damente, no sólo en México, sino en la mayoría de los países en desarrollo de ingresos medios, y los programas de protección social en salud tendrán que adaptarse a fin de enfrentar este nuevo reto.

Los resultados de la experiencia mexicana consistente en ofrecer protección financiera son positivos; sugieren el papel importante de la organización y el financiamiento del sistema de salud para aumentar la salud de la población, pero también para reducir el empobrecimiento, promover la equidad y proteger a los hogares durante los periodos de crisis financiera individual y colectiva.

\section{Agradecimientos}

Expresamos un agradecimiento especial en memoria de Mary Lorena. El corto tiempo que pasó con su familia se dedicó en parte a este trabajo y su recuerdo inspira a varios de sus autores para seguir dedicándose a mejorar el sector salud de México.

Deseamos agradecer a las siguientes personas su valiosa ayuda en la elaboración de este trabajo: Maja Pleic, Efrén Motta Santiago, Julio Frenk, Emmanuela Gakidou, Christopher Murray, Chunling Lu, Ana Mylena Aguilar-Rivera, Fabrizio Almazán Casali, Wendy Arrieta, Carlos Cabrera Hidalgo, Javier Dorantes, David Evans, María Agustina González, Miguel Angel Lezana, Rafael Lozano, Daniel Murcia, Teresa Nateras, Sonia X. Ortega, Teresa Pérez, Héctor Peña, Kyle Rattray y Francisco Javier Salcedo. Agradecemos los comentarios y sugerencias de los participantes en la Conferencia Internacional sobre Evidencia para la Reforma en Salud, en octubre de 2006. También deseamos agradecer al Instituto Nacional de Estadística, Geografía e Informática (INEGI) por la información; reconocer y agradecer al Centro Internacional para el Desarrollo de Investigaciones de Canadá (IDCR, por sus siglas en inglés) y a su programa Research Matters; al Health Financing Task Force; al Consejo Nacional de Ciencia y Tecnología (CONACYT), y al Grupo de Competitividad y Salud de la Fundación Mexicana para la Salud, así como a la Fundación misma, por el apoyo financiero e institucional brindado a este trabajo.

\section{Referencias}

I. Carrin G, James CD. Evans. Achieving Universal Health Coverage: Developing the Health Financing System. Technical Briefs for PolicyMakers No. I. Ginebra:World Health Organization, 2005. 2. Instituto Nacional de Estadística Geografía e Informática. Encuesta Nacional de Ingresos y Gastos de los Hogares. Aguascalientes, México: INEGI, I992, I994, 1996, I998, 2000, 2002, 2004. 
3. Instituto Nacional de Salud Pública y Secretaría de Salud. National Survey of Health and Nutrition. Cuernavaca, México: INSP, 2006. 4. World Bank. Income generation and social protection for the poor. Vol.I and Vol.2. México, DF:World Bank, 2005.

5. Instituto Nacional de Salud Pública. Evaluación externa de impacto del Programa Oportunidades. Cuernavaca, México: INSP, 2005. 6. Gakidou E, Lozano R, González-Pier E,Abbot-Klafter J, Barofsky JT, Bryson-Cahn C, et al. Evaluación del impacto de la Reforma Mexicana de Salud 200I-2006: un informe inicial. Salud Publica Mex 2007;49 supl I:S89-SII0.

7.Wagstaff $A, \operatorname{Van}$ Doorslaer E. Equity in the finance and delivery of health care:An introduction to the Equity Project. En: Barer ML, Getzen TE, Stoddart GL, ed. Health care and health economics: Perspectives on distribution. Sussex:Wiley, 1998: 179-207.

8. Wagstaff A, Van Doorsaler E. Equity in the finance of health care: Some further international comparisons. Health Econ 1999; 18:263-290. 9.World Health Organization. The World Health Report 2000. Health systems: Improving performance. Ginebra:WHO, 2000.

10. Frenk J, Lozano R, González Block MA, et al. Economía y salud: Propuesta para el avance del sistema de salud en México. Informe Final. México, DF: Fundación Mexicana para la Salud, 1994.

II. Xu K, Evans D, Carrin G, Aguilar-River AM. Designing Health Financing Systems to Reduce Catastrophic Health Expenditure. Technical Briefs for Policy-Makers No. 2. Ginebra:World Health Organization, 2005

12.Van Doorslaer E, O'Donnell O, Rannan-Eliya RP, et al. Effects of payments for health care on poverty estimates in II countries in Asia: an analysis of household survery data. Lancet 2006; 368: 1357-64.

13. Gertler P, Gruber J. Insuring consumption against illness. Amer Econ Rev 2002; 92:5।-70.

14. Himmelstein DU,Warren E, Thorne D, et al. Illness and injury as contributors to bankruptcy. Health Aff, web exclusive. 2 february, 2005. W5-64.

15. Londoño JL, Frenk J. Structured pluralism: Towards an innovative model for health system reform in Latin America. Health Policy 1997; $4|:|-36$

16. Frenk J.Tender puentes: lecciones globales desde México sobre políticas de salud basadas en evidencias. Salud Publica Mex 2007;49 supl I:SI4-S22.

17. Frenk J, González-Pier E, Gómez-Dantés O, Lezana MA, Knaul FM. Reforma integral para mejorar el desempeño del sistema de salud en México. Salud Publica Mex 2007;49 suppl I:S2I-S34.

18. Secretaría de Salud. Sistema de Protección en Salud: Hacia un sistema universal de salud. Firma del Decreto por el que se reforma y adiciona la Ley General de Salud. México, DF: Diario Oficial de la Federación, I5 de Mayo, 2003.

19. Knaul F, Frenk J. Health Insurance in Mexico: achieving universal coverage through structural reform. Health Aff 2005; 24: I 467-I 476. 20. Secretaría de Salud. Salud: México 2003. Información para la rendición de cuentas. México, DF: Secretaría de Salud, 2004.

21. Secretaría de Salud. Salud: México 2004. Información para la rendición de cuentas. México, DF: Secretaría de Salud, 2005.

22. Secretaría de Salud. Salud: México 200I-2005. Información para la rendición de cuentas. México, DF: Secretaría de Salud, 2006.

23. González-Pier E, Gutiérrez-Delgado C, Stevens G, Barraza-Lloréns $\mathrm{M}$, Porras-Condey $\mathrm{R}, \mathrm{Carvalho} \mathrm{N}$ et al. Definición de prioridades para las intervenciones de salud en el Sistema de Protección Social en Salud en México. Salud Publica Mex 2007;49 supl I:S37-S52.

24. Lozano R, Soliz P, Gakidou E,Abbott-Klafter J, Feehan D,Vidal C et al. Evaluación comparativa del desempeño de los sistemas estatales de salud usando cobertura efectiva. Salud Publica Mex 2007;49 supl I:S53-S69. 25. Londoño-de la Cuesta JL, Escobar ML, et al. La carga de la enfermedad en Colombia. Colombia: Ministerio de Salud de Colombia, 1994.
26. Frenk J, Knaul FM, Gómez-Dantés O. Closing the relevance-excellence gap in health research: the use of evidence in the Mexican health reform. Global Forum Update on Research for Health, 2005; 48-53.

27. Knaul FM, Arreola H, Méndez O, Miranda M. Preventing impoverishment, promoting equity and protecting households from financial crisis: universal health insurance through institutional reform in Mexico. Artículo presentado en la Global Development Network Conference, San Petersburgo, Rusia. Disponible en: http:// www.gdnet.org/pdf2/gdn_library/awards_medals/2005/ medals_cat3_first.pdf 28. Knaul F, Arreola H, Méndez O. Protección financiera en salud, México 1992 a 2004. Salud Publica Mex 2005; 47:430-439. 29. Secretaría de Salud. Salud: México 200I. Información para la rendición de cuentas. México, DF: Secretaría de Salud, 2002. 30. Secretaría de Salud. Salud: México 2002. Información para la rendición de cuentas. México, DF: Secretaría de Salud, 2003. 3I. Murray CJL, Knaul F, Xu K, et al. Defining and measuring fairness of financial contribution. WHO. Global Programme on Evidence Working Paper No 24, 2000. Ginebra: OMS, 2000 [consultado en: 17 de septiembre de 2006]. Disponible en: http://www.who.int/whosis/ discussion_papers/discussion_papers.cfm?path=whosis,evidence, discussion_papers\& language $=$ english\#.

32. Knaul F, Arreola $\mathrm{H}$, Méndez $\mathrm{O}$. The role of evidence on financial protection in the mexican health reform of 2003: identification, diagnosis, monitoring, prognosis and dissemination of learning. Working paper produced for the International Development Research Centre, Research Matters project, 2005. Disponible en: http://www.idrc.ca/ uploads/user_S/I I58745529I knaul_-_Mexico_Health_Reform.pdf. [consultado en: 3 de octubre de 2006]

33. Fuchs VR. Who shall live? Health, economics, and social choice. Great Britain:World Scientific Publications, 1998.

34. Banco de México. Mercado de cambios CFI02. Tipo de cambios diarios periodo 02/02/1992-24/08/2006. Mexico, DF: Banxico, 2006. http://www.banxico.org.mx/elnfoFinanciera/FSinfoFinanciera.html [consultado en: 25 de agosto de 2006].

35. Comisión Nacional de Salarios Mínimos. Salarios Mínimos: vigentes a partir del de enero de 2004. México, DF: Conasami, 2005. Disponible en: http://www.conasami.gob.mx/Archivos/ TABLA\%20DE\%20SALARIOS\%20 MINIMOS\%2OPROFESIONALES/ 2004.pdf. [consultado en: 24 de julio de 2006].

36. Federación Mexicana de Diabetes,A.C. Diabetes en números. México, DF: Federación Mexicana de Diabetes,A.C. 2006. Disponible en: http://www.fmdiabetes.com/www/diabetes/dnumeros.asp [consultado en: 24 de agosto de 2006].

37. Secretaría del Trabajo y Previsión Social. Estadísticas Laborales. México, DF: STPS, 2005. Disponible en: http://www.stps.gob.mx/ 0I_oficina/05_cgpeet/302_0057.htm [consultado en: 24 de agosto de 2006].

38. Comité Técnico para la Medición de la Pobreza. Medición de la Pobreza 2002-2004. México, DF: SEDESOL, 2005. Disponible en: http:// www.sedesol.gob.mx/prensa/comunicados/presentaciones/ MediciondelaPobreza2002-2004.ppt. [consultado en: 24 de agosto de 2006].

39. Arredondo A. Requerimientos Financieros para la Demanda de Servicios de Salud por Diabetes e Hipertensión. Rev Invest Clin 200I; 53: 422-429.

40. Knaul F, Arreola H, Méndez O, Leyva V. Catastrophic and impoverishing health expenditure: increasing risk pooling in the Mexican health system. Background paper for the regional study "Beyond survival: protecting households from the impoverishing effects of health shocks." Washington DC:World Bank, 2004.

41. Organization for Economic Co-operation and Development. OECD Reviews of Health Care Systems: Mexico/Paris: OECD, 2005. 
42. Secretaría de Desarrollo Social. Oportunidades: Informe de labores 2004. México, DF: Sedesol, 2005

43. Wagstaff A, Van Doorslaer E. Catastrophe and impoverishment in paying for health care: with applications to Vietnam 1993-98. Health Econ 2003; 12:921-934.

44. Baeza, C, Packard T. Beyond survival: protecting households from health shocks in Latin America. Washington DC:World Bank, 2006. 45. Mexican Commission on Macroeconomics and Health. To invest in health for economic development. Executive summary. Puebla, Mex: Universidad de la Américas, 2004.

46. Commision on Macroeconomics and Health. Macroeconomics and health: Investing in health for economic development. Report of the Commision on Macroeconomics and Health. Ginebra:WHO 2003.
47. Commission on Macroeconomics and Health. Tough choices: Investing in health for development: Experiences from national follow-up to the commission on Macroeconomics and health. Ginebra:WHO, 2006. 48. Knaul F, Arreola H, Méndez O, Torres, AC. Impoverishing and catastrophic household health spending among families with older adults in Mexico:A health reform priority. En:Angel J,Whitfield K ed. The health of aging hispanics: The Mexican-origin population. Nueva York: Springer Publishing Co.: En prensa. 